\title{
Effectiveness of National and Regional Sire Evaluations in Predicting Future-Daughter Milk Yield
}

\author{
H. D. Norman, ${ }^{1}$ P. M. VanRaden, ${ }^{1}$ R. L. Powell, ${ }^{1}$ J. R. Wright, ${ }^{1}$ and W. R. VerBoort ${ }^{2}$ \\ ${ }^{1}$ Animal Improvement Programs Laboratory, Agricultural Research Service, USDA, Beltsville, MD 20705 \\ ${ }^{2}$ California Dairy Herd Improvement Association, Clovis 93612
}

\begin{abstract}
National and regional bull evaluations were compared for ability to predict standardized milk yield of future daughters. Correlations between evaluations and first-, second-, and third-parity yields of future daughters were calculated within herd-year-month group. Mean correlations with predicted yield of future daughters across the United States were higher for national $(0.109,0.111$, and 0.082 for first, second, and third parities, respectively) than for Northeast (0.098, 0.085 , and 0.061) Holstein evaluations; corresponding correlations for future Northeast daughters were similar. Bull evaluations based on the first 5 parities of daughters that first calved through 1991 from either California, North Central, Northeast, or Southeast regions as well as from the entire United States were compared with standardized milk yields of daughters that calved later. Correlations with first-, second-, and third-parity yields of future daughters were higher (from 0.001 to 0.011 ) for national than for regional evaluations. National evaluations were better predictors of future-daughter yield, especially for California and the Southeast. Evaluations based on only first parity were slightly better than those based on the first 5 parities in predicting first-parity yield for 3 of 4 regions but were far less useful in predicting secondor third-parity yield regardless of region. Regional evaluations included fewer bulls because of limited numbers of daughters in each region. The top 100 bulls for genetic merit for milk yield based on regional rankings were inferior to the top 100 bulls based on national ranking by 25 to $173 \mathrm{~kg}$. Reliance on regional rather than national evaluations would reduce current US genetic gains.
\end{abstract}

(Key words: regional evaluation, genetic evaluation, yield prediction, genotype-environment interaction)

\footnotetext{
Received December 22, 2003.

Accepted August 29, 2004.

Corresponding author: H. D. Norman; e-mail: dnorman@aipl. arsusda.gov.
}

\begin{abstract}
Abbreviation key: EAIC = Eastern AI Cooperative, NEAISC $=$ Northeast AI Sire Comparison, MTCASE = multiple-trait cow and sire evaluation.
\end{abstract}

\section{INTRODUCTION}

In 1935, ADSA adopted plans for a proved sire program (Arnold, 1956). Those plans were to establish a central dairy records database in the USDA Bureau of Dairy Industry, Division of Dairy Herd Improvement Investigations (Hodgson, 1986). Records from cows throughout the United States were assembled so that sires could be evaluated using lactation yields of grade as well as registered daughters from all herds; milk and fat yields of each daughter were compared with yields of their dams. Since 1935, national sire evaluations have been calculated and released by USDA (King, 1973). A major improvement was made to national evaluations during 1960 by using the herdmate comparison method. Additional refinements to that method were incorporated during 1967 (Plowman and McDaniel, 1968). Enhancements such as including ancestor yield in sire evaluations, adjusting daughtercontemporary difference by genetic merit of contemporaries' sires, and improved weighting of daughter information across herds came with the Modified Contemporary Comparison during 1974 (Dickinson et al., 1976; Norman, 1976); inclusion of yield from all known relatives was implemented with the animal model during 1989 (Wiggans and VanRaden, 1989).

Before 1968, sire evaluations for milk and fat yields were calculated by several organizations. Every US dairy breed association calculated sire evaluations from cows enrolled in the DHI Registry test plan (Benson, 1985) and had recognition programs based on those records. During 1968, the US breed associations discontinued calculating genetic evaluations, and USDA evaluations became official for each breed. One reason given for discontinuing breed association evaluations for yield was that multiple evaluations based on different daughters and methods caused confusion for producers.

Other evaluations of various degrees of complexity have been and continue to be calculated, often by indi- 
vidual AI organizations, to provide an early indication of how bull daughters are milking before the next released USDA report. Usually, those preliminary examinations are used internally by AI organizations for semen collection decisions and have not been available to dairy producers. Thus, most breeders have had access only to evaluations published by USDA since 1968.

One exception is that dairy producers in the northeastern US are provided genetic evaluations that are calculated at Cornell University. A sire evaluation based on lactation records from New York was initiated after Henderson et al. (1954) proposed a herdmate comparison method. This evaluation was upgraded to the Northeast AI Sire Comparison (NEAISC), which was calculated with a sire model beginning in 1970 (Everett and Henderson, 1972), a sire model that incorporated the relationship matrix in 1976 (Everett and Quaas, 1979), a sire-maternal grandsire model in 1980 (Everett et al., 1979), and a multiple-trait sirematernal grandsire model in 1984 (Everett et al., 1983). In July 1989, a multiple-trait animal model was implemented (R. W. Everett, 1989, unpublished mimeograph) for Northeast cow and sire evaluations (MT-CASE), which was changed to a multiple-trait test-day model during 1994 (Everett and Schmitz, 1994).

Calculation and release of evaluations by Cornell University were based on the premise that those regional evaluations would more accurately reflect bull rankings for dairy producers in the Northeast than would national evaluations because of differences in methodology and data edits and existence of an interaction between genotype and region. The NEAISC evaluations were supported financially by Eastern AI Cooperative (EAIC; Ithaca, NY) under the premise that those evaluations would provide a more accurate ranking of EAIC bulls than did national evaluations. The possibility of a genotype-region interaction was the reason given for calculating and releasing a separate set of bull evaluations during 2003 based on milk records from only California DHIA herds (VerBoort, 2003).

The Northeast regional evaluations have incorporated innovative evaluation methodology [e.g., BLUP properties (Henderson, 1966) and the relationship matrix (Henderson, 1975)], but the existence of multiple sire evaluations has caused some confusion for dairy producers domestically and internationally. The Northeast regional and USDA national evaluation systems not only are based on different methodologies, but have different data editing procedures before analysis and different genetic bases.
Data from only first-parity records of daughters of AI bulls from the Northeast were included in NEAISC (Everett et al., 1983) and MT-CASE calculations. Evaluations from USDA include qualifying DHI records from all states; they also have included data from later parities in genetic evaluations continuously since 1935, a practice that has become standard for nearly all countries that participate in international evaluations (Interbull, 2004a). Records from the herd of the bull breeder or owner were excluded from Northeast regional evaluations. A herd-sire effect, which limited the influence of any single herd on an evaluation (Norman et al., 1972), was implemented for USDA evaluations. Records from some supervised a.m.-p.m. test plans were included in NEAISC evaluations earlier than in USDA evaluations. Many of the same differences continue between the current USDA animal model and the test-day model that is used to calculate both Northeast MT-CASE and California evaluations (California DHIA, 2003).

Breeders receive minimum guidance on how to use national and regional evaluations. Although some producers are aware of procedures that have been used to convert sire evaluations between countries (Wilmink et al., 1986; Weigel and Powell, 2000), similar conversion equations have never been provided for comparison of regional and national genetic evaluations. After the January 2003 release of California evaluations (California DHIA, 2003), California DHIA (Clovis, CA) expressed interest in determining the extent of any genotype-region effect. The release of the California evaluations also raised questions about similar concerns for other regions.

For lactation milk yield, Carabaño et al. (1990) estimated genetic correlations of 0.95 between California and New York and 0.94 between California and Wisconsin, both less than the correlation between New York and Wisconsin milk yields (0.99). Similarly, Rekaya et al. (2003) estimated genetic correlations for lactation milk yield of 0.95 between the southwestern and northeastern United States and 0.94 between the southwestern and midwestern United States, somewhat less than that between the northeastern and midwestern United States (0.97). Such high genetic correlations between geographic regions generally would not warrant calculation and release of unique regional evaluations. The Interbull Center (Uppsala, Sweden) produces unique evaluations for each contributing country, and May 2004 genetic correlations between countries for Holstein milk, fat, and protein yields ranged from 0.75 to 0.96 (Interbull, 2004b).

Regional evaluations could provide more accurate information for producers in the region where the lactation records originated than would a national evalu- 
ation if the genotype-region interaction were large. Objectives of this study were to compare how well national and regional evaluations predict daughter yield in the Northeast across time with various evaluation methods and to determine whether regional evaluations are likely to improve prediction of daughter performance in 4 geographical areas with different climatic conditions.

\section{MATERIALS AND METHODS}

\section{Historical Comparison of Northeast and National Sire Evaluations}

Data. Evaluations released in the January NEAISC from 1976 through 1987 and in the Northeast MTCASE from July 1994 and 1995 were matched with corresponding USDA-DHIA evaluations from the same year and month for Ayrshire, Guernsey, Holstein, and Jersey AI bulls. Brown Swiss were excluded because few bulls had Northeast evaluations.

Only milk records of bull daughters that were identified in DHI herds and born from matings after the evaluation release date were designated as yield of future daughters. Lactation records were standardized to a mature-equivalent basis for age, calving month, milking frequency, and lactation length with procedures used for national evaluations at the time of evaluation release (Wiggans and Dickinson, 1985). Adjustment factors for calving age and month for the NEAISC and USDA evaluation systems had been developed from essentially the same model during the early 1970s (Miller, 1973; Norman et al., 1974). Factors to project records with $<305$ DIM for NEAISC and USDA evaluations also were developed with essentially the same model at nearly the same time (Wiggans and Van Vleck, 1979; Wiggans and Powell, 1980). Therefore, differences caused by yield standardization procedures should be minimal. Factors used to standardize yield for comparison of 1994 and 1995 evaluations are those still currently in use for national evaluations (VanRaden et al., 1995, 1999).

Methods. Northeast and national evaluations were used to predict standardized milk yields of future daughters for first, second, and third parities. Predicted yields based on January NEAISC and USDA evaluations from 1976 through 1987 were compared with actual standardized yields from daughters born after the following October of the evaluation year and calving before May 1991; e.g., predicted yields based on January 1976 evaluations were compared with yields of daughters born after October 1976 and calving before May 1991. A May 1991 cutoff for calving was used because examination of 1976 through 1987 evaluations had been completed by mid1991. A sepa- rate comparison was done for standardized yields from each of the first 3 parities; therefore, any differences because of age adjustment should be small. However, other adjustments associated with each evaluation system would influence results: the more accurate the adjustments, the higher the correlation within herdyear-month group that would be expected between evaluations and future-daughter yield.

A similar prediction analysis was repeated for bull evaluations that were released during July 1994 and 1995. Predicted standardized milk yield of future daughters based on Northeast (MT-CASE) and national (USDA animal model) evaluations was compared with standardized yield from daughters born after the following April and calving before January 2003. July 1994 was selected because the Northeast evaluation system began then to include lactation yields that had been adjusted for environmental effects of test days before analysis. The 2 evaluation procedures (MT-CASE for Northeast evaluations and USDA animal model for national evaluations) are nearly identical to those presently used in the Northeast and nationally for released evaluations and should reflect the accuracy of information provided by each to breeders today.

Prediction accuracy was the correlation between bull evaluation and standardized yield of future daughters within herd-year-month group. Month groups were defined as January through June and July through December. Groups with fewer months (1, 2 , or 3 ) were also examined to determine the possible impact of adjustment factors for calving month used for both NEAISC and USDA evaluations. Because group length was found to have no consistent effect on prediction accuracy, 6-mo groups were chosen to increase the number of cows compared within group.

The impact of assortative mating on the usefulness of sire evaluations in predicting first-parity milk yield for Holsteins was determined by subtracting the dam's PTA for milk yield from the daughter's standardized milk yield. This impact was expected to be small because correlation between merit of sire and dam calculated within-herd-year was near zero for all breeds except Ayrshire from 1967 through 1984 (Norman et al., 1987). To ensure sufficient accuracy of adjustment for merit of mate and to eliminate the possibility of large changes from unknown-parent grouping, dam PTA was required to have a reliability (repeatability) of $>35 \%$ for daughter information to be included in the analysis for assortative mating.

Powell and Norman (1986) reported a bias (95 kg) due to preferential treatment between registered and grade animals in mixed-registry herds. Although registered and grade cows were not segregated into sepa- 


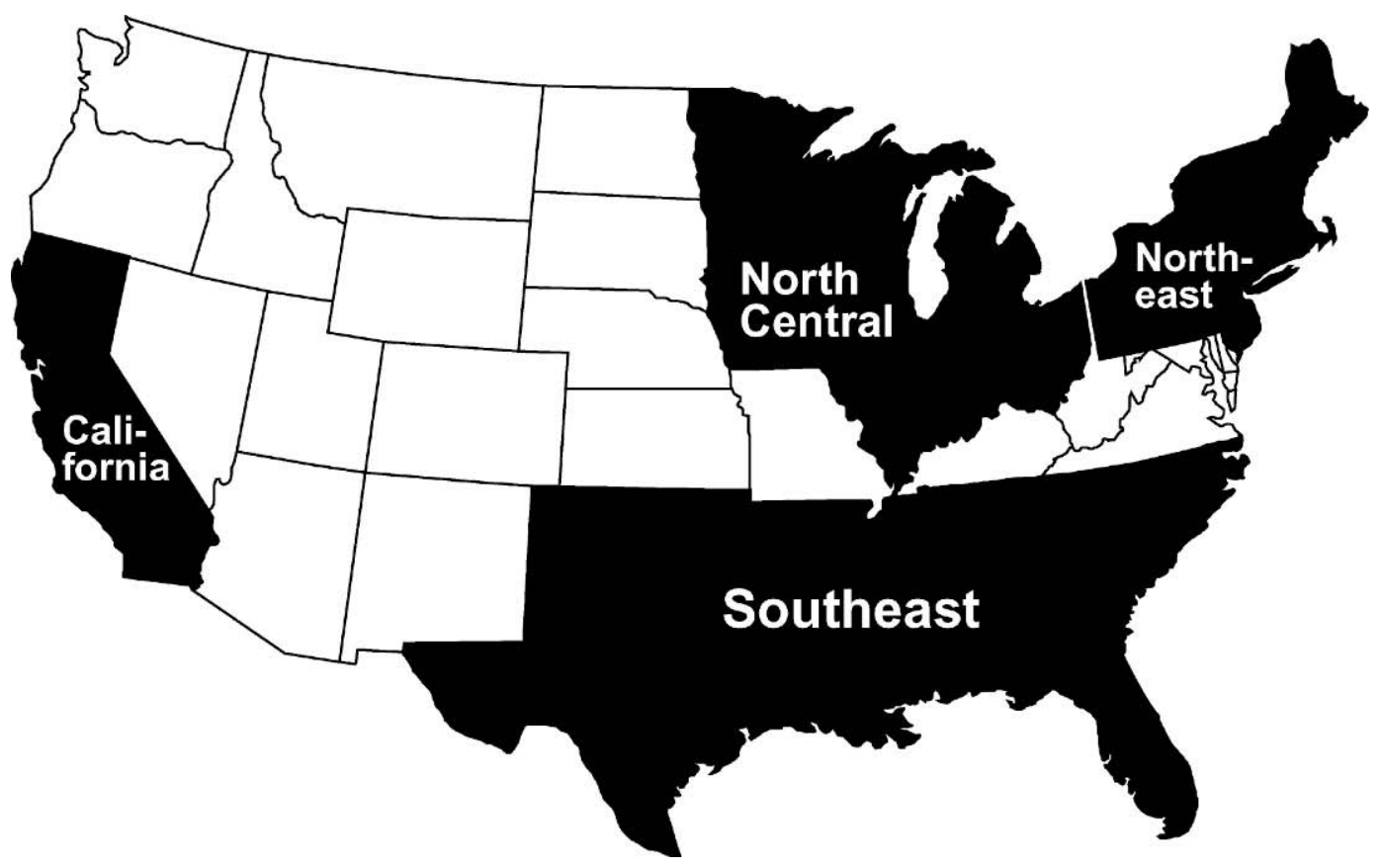

Figure 1. Definition of US regions for regional genetic evaluations (California; North Central = Illinois, Indiana, Iowa, Michigan, Minnesota, Ohio, and Wisconsin; Northeast = Connecticut, Maine, Massachusetts, New Hampshire, New Jersey, New York, Pennsylvania, Rhode Island, and Vermont; and Southeast = Alabama, Arkansas, Florida, Georgia, Louisiana, Mississippi, North Carolina, Oklahoma, South Carolina, Tennessee, and Texas).

rate management groups from 1976 through 1987 for either Northeast or national evaluations, they were for all 1994 and 1995 evaluations. Nevertheless, differences from preferential treatment were expected to affect Northeast and national evaluations similarly, and any bias was assumed too small to invalidate comparison of evaluations for predictability of futuredaughter yield.

Correlations between each bull evaluation and yield of future daughters from all states were compared with correlations between each evaluation and yield of future daughters that were milked in the Northeast to determine whether the genotype-environment interaction was large enough to have caused bull daughters to perform differently.

Accuracy of sire evaluations in predicting futuredaughter yield also was examined in relation to controlling AI organization for each bull as determined by controller code assigned by the National Association of Animal Breeders (2003; Columbia, MO). Correlations between evaluations and future-daughter yields were computed separately for future daughters sired by EAIC bulls (controller code 003 for evaluation years 1976 through 1985 and code 008 for 1986 and 1987 evaluations) and those sired by bulls from other AI organizations. Accuracy of prediction of yield performance of future daughters might differ between EAIC and other bulls because most progeny-test daughters of EAIC bulls were located in the Northeast, which was not the case for bulls from other AI organizations. Prediction accuracy also could be affected by different sampling methods used by AI organizations.

\section{Determination of Potential Benefit from Regional Sire Evaluation}

Data. Lactation milk records for parities 1 through 5 of Holsteins in California and North Central, Northeast, and Southeast United States (Figure 1) were used to calculate regional sire evaluations for comparison with sire evaluations based on records from the entire United States. Sire evaluations were limited to AI bulls with controller codes of $<245$ as assigned by the National Association of Animal Breeders (2003). Bulls were required to have $\geq 20$ daughters in a region to receive a regional evaluation.

Methods. All regional and national sire evaluations were computed with the current USDA-DHIA animal model procedure (Wiggans and VanRaden, 1989) and lactation records of bull daughters with a first calving date before January 1, 1992. Records from later parities were excluded if the cow changed herds. To evaluate the impact of parity, both regional and national evaluations were calculated with only first-parity re- 
cords and with records from all (first through fifth) parities. Regional and national evaluations were compared for ability to predict standardized milk yield within herd-year-season of future daughters (those with first calvings from January 1, 1992, through January 10,2003 ; i.e., after the cutoff date for data inclusion in national genetic evaluations) for each region and nationally. Both completed and in-progress records of future daughters were included.

Realized genetic progress is influenced not only by evaluation accuracy but also by the extent to which the evaluation source is used. Therefore, future genetic progress was estimated for 3 scenarios for bull selection: 1) top bulls from regional evaluation based on all parities of daughters, 2) top bulls from regional evaluation based on first parity of daughters, and 3) top bulls from national evaluation based on all parities of daughters. To allow comparison of evaluations on a regional basis, equations were developed to convert national to regional evaluations for each of the various regions by applying the method of Wilmink et al. (1986) to information from bulls with $\geq 20$ daughters in the region. The ability of regional and converted national evaluations to estimate genetic progress was assessed by comparing mean PTA milk for the top 25, 50 , or 100 bulls based on converted national PTA with mean PTA milk for the top 25, 50, or 100 bulls based on actual regional PTA. Difference in mean PTA milk is expected to show the loss or gain that dairy producers would have experienced (on an annual, per cow basis) from limiting breeding choices to bulls evaluated in each of the 4 regions if such regional sire evaluations had been available during 1992. A similar comparison was made for the top Northeast bulls based on 1994 and 1995 MT-CASE evaluations.

\section{RESULTS AND DISCUSSION}

\section{Historical Comparison of Northeast and National Sire Evaluations}

Bulls with both Northeast regional and USDA national evaluations (Table 1) were primarily bulls with semen available for AI marketing. The number of Holstein AI bulls with Northeast and USDA evaluations in the same year from 1976 through 1987 and 1994 through 1995 ranged from 84 to 182 ; numbers for other breeds ranged from 2 to 28 . Numbers of bulls varied considerably over time; Holstein and Jersey increases reflected growth in progeny-test programs (Norman et al., 2001). Some fluctuations could indicate changes in release criteria for bull evaluations.

Correlations between Northeast regional and USDA national evaluations for milk yield (Table 1) ranged from 0.78 to 0.84 for Holsteins across years. Everett et al. (1983) reported a correlation of 0.80 between 1979 NEAISC and USDA evaluations. Correlations ranged from 0.20 to 1.00 for other breeds, with large yearly fluctuations for breeds with a small population size. A high percentage of bulls with Northeast evaluations, especially those from AI organizations other than EAIC, had re-entered AI service following progeny testing. Because those bulls were a selected subset of the AI bulls sampled (many had passed intense screening for milk yield) and Northeast evaluations were computed from only a portion of the records available (first parities of cows in the Northeast), lower correlations with USDA evaluations would be expected than if NEAISC evaluations also had been available for bulls that had not passed screening. Only EAIC sampled its bulls exclusively in the Northeast.

For calculation of correlations of evaluations with standardized first-parity milk yield of future daughters within herd-year-season (Table 2), >160,000 lactation records generally were available annually for Holsteins. However, because each bull's transmitting ability was repeated for each daughter, the correlations were a function of number of bulls included, USDA reliability, and NEAISC or MT-CASE confidence range for each evaluation.

In general, national evaluations calculated by USDA more accurately predicted first-parity standardized milk yield of future Holstein daughters throughout the United States than did Northeast evaluations. Correlation with first-parity yield of future daughters was higher for USDA evaluations than for NEAISC evaluations for 9 of $12 \mathrm{yr}$, the same for $1 \mathrm{yr}$, and lower for $2 \mathrm{yr}$. Mean correlation of evaluations from 1976 through 1987 with yield was 0.109 for USDA evaluations and 0.098 for NEAISC evaluations. Correlation with first-parity yield was higher by 0.01 for USDA evaluations than for MT-CASE evaluations for 1994 and 1995 even though those Northeast evaluations were based on a test-day model.

When standardized first-parity milk yield of future daughters was adjusted for genetic merit of dam (dam PTA), correlation with adjusted yield was higher for USDA evaluations than for NEAISC evaluations for 9 of $12 \mathrm{yr}$, the same for $2 \mathrm{yr}$, and lower for $1 \mathrm{yr}$ (Table 2). Mean correlation of evaluations from 1976 through 1987 with adjusted future-daughter yield was 0.125 for USDA evaluations and 0.112 for NEAISC evaluations, which was somewhat higher than for unadjusted yield; however, differences in method accuracy changed little across years. Because correction for merit of mates had no apparent effect on how evaluation methods ranked for predicting future-daughter yield, that adjustment was not included in additional analyses so that data could be maximized and comput- 
Table 1. Numbers of bulls with both a Northeast regional ${ }^{1}$ and a USDA national ${ }^{2}$ evaluation for milk yield and correlations between those evaluations by breed and evaluation year. ${ }^{3}$

\begin{tabular}{|c|c|c|c|c|c|c|c|c|}
\hline \multirow[b]{2}{*}{ Year } & \multicolumn{2}{|c|}{ Ayrshire } & \multicolumn{2}{|c|}{ Guernsey } & \multicolumn{2}{|c|}{ Holstein } & \multicolumn{2}{|c|}{ Jersey } \\
\hline & Bulls & Correlation & Bulls & Correlation & Bulls & Correlation & Bulls & Correlation \\
\hline & (no.) & & (no.) & & (no.) & & (no.) & \\
\hline 1976 & 11 & 0.44 & 5 & 0.82 & 96 & 0.83 & 8 & 0.65 \\
\hline 1977 & 8 & 0.75 & 7 & 0.86 & 96 & 0.82 & 8 & 0.91 \\
\hline 1978 & 7 & 0.56 & 4 & 0.93 & 84 & 0.78 & 12 & 0.73 \\
\hline 1979 & 9 & 0.55 & 8 & 0.59 & 95 & 0.79 & 9 & 0.51 \\
\hline 1980 & 6 & 0.69 & 4 & 0.69 & 94 & 0.82 & 10 & 0.90 \\
\hline 1981 & 9 & 0.37 & 3 & 0.92 & 115 & 0.81 & 16 & 0.84 \\
\hline 1982 & 2 & 1.00 & 5 & 0.91 & 98 & 0.80 & 14 & 0.87 \\
\hline 1983 & 6 & 0.91 & 6 & 0.66 & 100 & 0.83 & 13 & 0.92 \\
\hline 1984 & 9 & 0.80 & 13 & 0.85 & 149 & 0.82 & 24 & 0.84 \\
\hline 1985 & 14 & 0.90 & 8 & 0.82 & 177 & 0.82 & 28 & 0.82 \\
\hline 1986 & 8 & 0.96 & 5 & 0.94 & 145 & 0.78 & 23 & 0.78 \\
\hline 1987 & 11 & 0.86 & 8 & 0.86 & 136 & 0.78 & 17 & 0.72 \\
\hline 1994 & 11 & 0.58 & 9 & 0.20 & 182 & 0.84 & 19 & 0.88 \\
\hline 1995 & 5 & 0.97 & 2 & 1.00 & 174 & 0.78 & 19 & 0.75 \\
\hline
\end{tabular}

${ }^{1}$ Calculated with a sire model with relationship matrix from 1976 through 1979 , a sire-maternal grandsire model from 1980 through 1983, a multiple-trait sire-maternal grandsire model from 1984 through 1987, and a multiple-trait test-day model during 1994 and 1995

${ }^{2}$ Calculated with the Modified Contemporary Comparison from 1976 through 1987 and an animal model during 1994 and 1995.

${ }^{3}$ January evaluation for 1976 through 1987; July evaluation for 1994 and 1995.

ing resources minimized. Nevertheless, including an adjustment for dam PTA reduced available data by $27 \%$ because not all dams had identification data and a minimum reliability of $35 \%$ was imposed for dam PTA.

Correlations of both Northeast and USDA evaluations with first-parity milk yield of future daughters were lower for 1994 and 1995 than for earlier years (Table 2). The reason for this decline is difficult to determine without an extensive investigation. However, one influence on the correlations is variation in PTA among cow sires, which is impacted by selection intensity practiced after progeny testing. If evaluations of bulls that were marketed during recent years are more similar (smaller standard deviation) than those of bulls marketed during earlier years because of increased selection intensity by AI organizations, the recent correlations should be lower (Powell and Norman, 1988). For example, evaluations of bulls used as cow sires would have no predictive ability if their PTA after selection were all the same.

The number of bulls that were returned to AI service compared with the number that entered AI sampling decreased from 1 in 3 around 1970 to 1 in 8 around 1990 (Norman et al., 2003), which reduced the variation in PTA of selected bulls. The extent to which those bulls are used as sires also impacts the correlation of PTA with future-daughter yield: the higher the proportion of matings made to the top-ranked bulls, the lower the correlation of sire PTA with future-daughter performance (Powell and Norman, 1988). As the best bull is used more extensively, that correlation approaches zero. Because the proportion of bulls returned to service and the subsequent frequency of their use as sires impact correlations of their evaluations with future-daughter yield, concern about whether the lower correlations found for 1994 and 1995 indicate that evaluation methods are becoming less effective over time appears to be unwarranted.

Holstein analyses included between 22,943 and 219,138 second- and third-parity records for each yearparity group (Table 3). Fewer records were available for later parities than for first because of culling as well as insufficient time for some cows to calve again and milk for an entire lactation, especially for later years. Second-parity standardized milk yield of future Holstein daughters was predicted more accurately by USDA evaluations than by NEAISC evaluations for all $11 \mathrm{yr}$ (Table 3). Mean correlation of evaluations from 1976 through 1986 with second-parity yield was 0.111 for USDA evaluations and 0.082 for NEAISC evaluations. Correlations of USDA evaluations with second-parity yield generally were slightly higher than correlations with first-parity yield (Table 2) before 1983 but slightly lower after 1983. For Northeast evaluations, correlations with second-parity yield generally were lower than with first-parity yield, which is expected because Northeast evaluations were based on only first-parity records. National evaluations calculated by USDA predicted second-parity yield of fu- 
Table 2. Numbers of first-parity records and herd-year-seasons ${ }^{1}$ for US Holstein cows that completed those records after release date of evaluations for their sires and correlations within herd-year-season between first-parity standardized ${ }^{2}$ milk yield of future Holstein daughters with or without adjustment for genetic merit of dams and Northeast regional ${ }^{3}$ or USDA national ${ }^{4}$ evaluations by evaluation year. $^{5}$

\begin{tabular}{|c|c|c|c|c|c|}
\hline \multirow{2}{*}{$\begin{array}{l}\text { Adjustment } \\
\text { for dam merit }\end{array}$} & \multirow[b]{2}{*}{ Year } & \multirow[b]{2}{*}{ Records } & \multirow{2}{*}{$\begin{array}{l}\text { Herd-year- } \\
\text { seasons }\end{array}$} & \multicolumn{2}{|c|}{$\begin{array}{c}\text { Correlation with } \\
\text { future-daughter yield }\end{array}$} \\
\hline & & & & USDA & Northeast \\
\hline & & 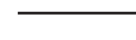 & & & \\
\hline \multirow[t]{14}{*}{ None } & 1976 & 262,919 & 119,284 & 0.09 & 0.08 \\
\hline & 1977 & 284,060 & 118,172 & 0.10 & 0.09 \\
\hline & 1978 & 282,632 & 103,568 & 0.09 & 0.07 \\
\hline & 1979 & 293,532 & 108,834 & 0.08 & 0.09 \\
\hline & 1980 & 227,141 & 83,372 & 0.10 & 0.10 \\
\hline & 1981 & 216,867 & 86,849 & 0.10 & 0.09 \\
\hline & 1982 & 182,539 & 69,344 & 0.13 & 0.15 \\
\hline & 1983 & 187,269 & 73,176 & 0.15 & 0.13 \\
\hline & 1984 & 321,205 & 103,307 & 0.12 & 0.11 \\
\hline & 1985 & 291,418 & 90,139 & 0.13 & 0.10 \\
\hline & 1986 & 192,214 & 60,115 & 0.12 & 0.10 \\
\hline & 1987 & 71,904 & 28,691 & 0.10 & 0.07 \\
\hline & 1994 & 238,004 & 103,795 & 0.09 & 0.08 \\
\hline & 1995 & 166,412 & 77,036 & 0.07 & 0.06 \\
\hline \multirow[t]{12}{*}{ Adjusted } & 1976 & 191,720 & 95,482 & 0.11 & 0.09 \\
\hline & 1977 & 203,970 & 95,056 & 0.12 & 0.11 \\
\hline & 1978 & 202,778 & 85,508 & 0.11 & 0.09 \\
\hline & 1979 & 210,932 & 89,506 & 0.10 & 0.10 \\
\hline & 1980 & 158,154 & 66,966 & 0.12 & 0.12 \\
\hline & 1981 & 154,083 & 69,216 & 0.11 & 0.10 \\
\hline & 1982 & 131,996 & 56,287 & 0.16 & 0.17 \\
\hline & 1983 & 132,789 & 58,211 & 0.16 & 0.14 \\
\hline & 1984 & 244,656 & 85,890 & 0.13 & 0.12 \\
\hline & 1985 & 215,035 & 73,879 & 0.14 & 0.12 \\
\hline & 1986 & 143,640 & 49,400 & 0.13 & 0.11 \\
\hline & 1987 & 53,638 & 23,102 & 0.11 & 0.08 \\
\hline \multicolumn{6}{|c|}{${ }^{1}$ Seasons defined as January to June and July to December. } \\
\hline \multicolumn{6}{|c|}{$\begin{array}{l}{ }^{3} \text { Calculated with a sire model with relationship matrix from } 1976 \text { through } 1979 \text {, a sire-maternal grandsire } \\
\text { model from } 1980 \text { through } 1983 \text {, a multiple-trait sire-maternal grandsire model from } 1984 \text { through } 1987 \\
\text { and a multiple-trait test-day model during } 1994 \text { and } 1995 .\end{array}$} \\
\hline \multicolumn{6}{|c|}{$\begin{array}{l}{ }^{4} \text { Calculated with the Modified Contemporary Comparison from } 1976 \text { through } 1987 \text { and an animal mode } \\
\text { during } 1994 \text { and } 1995 .\end{array}$} \\
\hline
\end{tabular}

ture daughters better than did MT-CASE evaluations by 0.01 for 1994 and equally for 1995 .

Third-parity standardized milk yield of future Holstein daughters was predicted more accurately by USDA evaluations than by NEAISC evaluations for 9 of $10 \mathrm{yr}$ (Table 3). Mean correlation of evaluations from 1976 through 1985 with third-parity yield was 0.085 for USDA evaluations and 0.061 for NEAISC evaluations. Mean correlation of Holstein bull evaluations with third-parity yield was lower than with first- or second-parity yield for both USDA and NEAISC evaluations; differences between correlations of evaluations with first- and third-parity yield were larger for recent years. National evaluations calculated by USDA predicted third-parity yield of future daughters better than did MT-CASE evaluations by 0.01 for both 1994 and 1995.
Corresponding correlations of bull evaluations with standardized yield of future daughters were calculated for Ayrshires, Guernseys, and Jerseys (not shown). Correlation with first-parity yield was the same or higher for USDA evaluations than for NEAISC evaluations for 8 of $9 \mathrm{yr}$ for Ayrshires, 6 of $10 \mathrm{yr}$ for Guernseys, and 9 of $10 \mathrm{yr}$ for Jerseys. Correlation with secondparity yield was the same or higher for USDA than for NEAISC evaluations for 7 of $9 \mathrm{yr}$ for Ayrshires and 8 of $10 \mathrm{yr}$ for Jerseys, but only 5 of $10 \mathrm{yr}$ for Guernseys. Correlation of USDA evaluations with third-parity yield was the same or higher for 5 of $6 \mathrm{yr}$ for Ayrshires, 5 of $9 \mathrm{yr}$ for Guernseys, and 8 of $10 \mathrm{yr}$ for Jerseys.

The existence of a large genotype-environment interaction would give an advantage to USDA evaluations compared with NEAISC or MT-CASE evaluations for predicting standardized milk yield of future 
Table 3. Numbers of second- and third-parity records and herd-year-seasons ${ }^{1}$ for US Holstein cows that completed those records after release date of evaluations for their sires and correlations within herd-yearseason between standardized ${ }^{2}$ milk yield from corresponding parity of future daughters and Northeast regional $^{3}$ or USDA national ${ }^{4}$ evaluations by evaluation year. ${ }^{5}$

\begin{tabular}{|c|c|c|c|c|c|}
\hline \multirow[b]{2}{*}{ Parity } & \multirow[b]{2}{*}{ Year } & \multirow[b]{2}{*}{ Records } & \multirow{2}{*}{$\begin{array}{l}\text { Herd-year- } \\
\text { seasons }\end{array}$} & \multicolumn{2}{|c|}{$\begin{array}{c}\text { Correlation with } \\
\text { future-daughter yield }\end{array}$} \\
\hline & & & & USDA & Northeast \\
\hline \multirow{14}{*}{2} & & & & & \\
\hline & 1976 & 204,948 & 103,056 & 0.10 & 0.08 \\
\hline & 1977 & 219,138 & 101,458 & 0.11 & 0.10 \\
\hline & 1978 & 214,507 & 87,757 & 0.10 & 0.06 \\
\hline & 1979 & 218,387 & 90,823 & 0.10 & 0.09 \\
\hline & 1980 & 167,042 & 68,850 & 0.10 & 0.09 \\
\hline & 1981 & 155,366 & 69,466 & 0.11 & 0.06 \\
\hline & 1982 & 123,450 & 51,889 & 0.14 & 0.13 \\
\hline & 1983 & 121,386 & 52,526 & 0.14 & 0.09 \\
\hline & 1984 & 187,106 & 68,516 & 0.08 & 0.04 \\
\hline & 1985 & 135,972 & 50,370 & 0.12 & 0.07 \\
\hline & 1986 & 38,286 & 19,415 & 0.12 & 0.09 \\
\hline & 1994 & 159,101 & 85,125 & 0.08 & 0.07 \\
\hline & 1995 & 108,732 & 60,060 & 0.05 & 0.05 \\
\hline \multirow[t]{12}{*}{3} & 1976 & 146,761 & 82,749 & 0.09 & 0.06 \\
\hline & 1977 & 155,191 & 80,817 & 0.08 & 0.07 \\
\hline & 1978 & 148,540 & 68,730 & 0.07 & 0.05 \\
\hline & 1979 & 146,940 & 69,317 & 0.07 & 0.07 \\
\hline & 1980 & 111,508 & 52,090 & 0.08 & 0.07 \\
\hline & 1981 & 99,883 & 50,357 & 0.09 & 0.04 \\
\hline & 1982 & 74,848 & 35,262 & 0.11 & 0.10 \\
\hline & 1983 & 64,364 & 31,577 & 0.11 & 0.08 \\
\hline & 1984 & 73,241 & 33,510 & 0.07 & 0.03 \\
\hline & 1985 & 22,943 & 13,689 & 0.08 & 0.04 \\
\hline & 1994 & 92,089 & 54,957 & 0.07 & 0.06 \\
\hline & 1995 & 56,451 & 34,491 & 0.05 & 0.04 \\
\hline
\end{tabular}

\footnotetext{
${ }^{1}$ Seasons defined as January to June and July to December.

${ }^{2}$ Mature-equivalent basis for age, calving month, milking frequency, and lactation length.

${ }^{3}$ Calculated with a sire model with relationship matrix from 1976 through 1979, a sire-maternal grandsire model from 1980 through 1983, a multiple-trait sire-maternal grandsire model from 1984 through 1987, and a multiple-trait test-day model during 1994 and 1995.

${ }^{4}$ Calculated with the Modified Contemporary Comparison from 1976 through 1987 and an animal model during 1994 and 1995.

${ }^{5}$ January evaluation for 1976 through 1987; July evaluation for 1994 and 1995.
}

daughters across the entire country. However, the observed advantage of USDA evaluations over Northeast evaluations also could result from 1) including additional daughters, 2) including records from later parities, 3) different rates of daughter maturity, or 4) different accuracy of evaluation procedures. Because those 4 alternative causes were at least partially confounded, determining an exact explanation for the observed difference in prediction accuracy between USDA and Northeast evaluations is difficult. Some advantage for USDA evaluations in predicting second- and thirdparity yields probably can be attributed to the inclusion of later-parity information in those evaluations, because the genetic correlation between first- and later-parity yields generally has been estimated to be $<1.0$ (Cassell and McDaniel, 1983). Previous research (Powell et al., 1981; Cassell et al., 1985) reported dif- ferences in predictability of lactation records by parity, depending on whether first, second, or later parity was the target.

In contrast, the existence of a large genotype-environment interaction would give an advantage to NEAISC or MT-CASE evaluations compared with USDA evaluations for predicting standardized milk yield of future daughters within the Northeast. Because correlations of evaluations with second-parity records of all future daughters (Table 3) were intermediate to correlations with first- (Table 2) and thirdparity records (Table 3), correlations of evaluations with yield of future Northeast Holstein daughters were calculated only for first- and third-parity records (Table 4). The number of added daughter records in the Northeast was $54 \%$ of that for the United States. First-parity milk yield of future Northeast daughters 
Table 4. Numbers of first- and third-parity records and herd-year-seasons ${ }^{1}$ for Northeast Holstein cows that completed those records after release date of evaluations for their sires and correlations within herdyear-season between standardized ${ }^{2}$ milk yield from corresponding parity of future daughters and Northeast regional $^{3}$ or USDA national ${ }^{4}$ evaluations based on all or first-parity lactation records by evaluation year. ${ }^{5}$

\begin{tabular}{|c|c|c|c|c|c|c|}
\hline \multirow[b]{3}{*}{ Parity } & \multirow[b]{3}{*}{ Year } & \multirow[b]{3}{*}{ Records } & \multirow{3}{*}{$\begin{array}{l}\text { Herd-year- } \\
\text { seasons }\end{array}$} & \multicolumn{3}{|c|}{ Correlation with future-daughter yield } \\
\hline & & & & \multicolumn{2}{|c|}{ USDA } & \multirow[b]{2}{*}{ Northeast } \\
\hline & & & & All parities & First parity & \\
\hline & & $\longrightarrow$ & .) & & & \\
\hline \multirow[t]{14}{*}{1} & 1976 & 124,493 & 45,515 & 0.09 & 0.07 & 0.07 \\
\hline & 1977 & 152,027 & 50,124 & 0.11 & 0.11 & 0.10 \\
\hline & 1978 & 177,400 & 51,049 & 0.10 & 0.11 & 0.07 \\
\hline & 1979 & 173,345 & 48,132 & 0.08 & 0.08 & 0.08 \\
\hline & 1980 & 139,674 & 39,178 & 0.10 & 0.11 & 0.10 \\
\hline & 1981 & 115,105 & 33,277 & 0.09 & 0.11 & 0.08 \\
\hline & 1982 & 112,238 & 32,469 & 0.14 & 0.15 & 0.16 \\
\hline & 1983 & 97,868 & 28,080 & 0.16 & 0.16 & 0.13 \\
\hline & 1984 & 162,243 & 46,446 & 0.12 & 0.13 & 0.11 \\
\hline & 1985 & 136,157 & 38,596 & 0.13 & 0.13 & 0.11 \\
\hline & 1986 & 92,859 & 25,849 & 0.12 & 0.13 & 0.11 \\
\hline & 1987 & 32,649 & 12,148 & 0.11 & 0.11 & 0.08 \\
\hline & 1994 & 92,157 & 39,869 & 0.11 & $\ldots$ & 0.10 \\
\hline & 1995 & 64,203 & 29,366 & 0.10 & $\ldots$ & 0.08 \\
\hline \multirow[t]{12}{*}{3} & 1976 & 75,557 & 35,670 & 0.09 & 0.05 & 0.07 \\
\hline & 1977 & 89,774 & 38,704 & 0.08 & 0.07 & 0.07 \\
\hline & 1978 & 100,527 & 38,526 & 0.07 & 0.09 & 0.04 \\
\hline & 1979 & 92,927 & 35,042 & 0.07 & 0.07 & 0.06 \\
\hline & 1980 & 72,742 & 27,822 & 0.08 & 0.07 & 0.07 \\
\hline & 1981 & 56,460 & 22,290 & 0.08 & 0.06 & 0.02 \\
\hline & 1982 & 48,383 & 18,464 & 0.12 & 0.11 & 0.12 \\
\hline & 1983 & 34,754 & 13,412 & 0.12 & 0.12 & 0.08 \\
\hline & 1984 & 38,407 & 16,205 & 0.09 & 0.08 & 0.04 \\
\hline & 1985 & 10,807 & 6,506 & 0.09 & 0.08 & 0.04 \\
\hline & 1994 & 39,022 & 23,049 & 0.08 & $\ldots$ & 0.07 \\
\hline & 1995 & 20,572 & 11,948 & 0.07 & $\ldots$ & 0.07 \\
\hline
\end{tabular}

${ }^{1}$ Seasons defined as January to June and July to December.

${ }^{2}$ Mature-equivalent basis for age, calving month, milking frequency, and lactation length.

${ }^{3}$ Calculated with a sire model with relationship matrix from 1976 through 1979, a sire-maternal grandsire model from 1980 through 1983, a multiple-trait sire-maternal grandsire model from 1984 through 1987, and a multiple-trait test-day model during 1994 and 1995.

${ }^{4}$ Calculated with the Modified Contemporary Comparison from 1976 through 1987 and an animal model during 1994 and 1995; first-parity evaluations were calculated from 1976 through 1987 but not released to producers and were not calculated during 1994 and 1995.

${ }^{5}$ January evaluation for 1976 through 1987; July evaluation for 1994 and 1995.

was predicted more accurately by USDA evaluations based on all lactation records than by NEAISC evaluations for 9 of $12 \mathrm{yr}$; NEAISC evaluations predicted first-parity yield better only for 1982. Mean correlation of evaluations from 1976 through 1987 with first-parity lactation yield of future Northeast Holstein daughters was 0.113 for USDA evaluations and 0.100 for NEAISC evaluations, which was nearly identical to the corresponding correlation for yield from all future US daughters for both evaluation methods. Therefore, no apparent interaction between genotype and environment was indicated for Holsteins that would cause bulls to rank differently in the Northeast than in the entire United States, and genotype-environment interaction was eliminated as a cause of the difference in the 2 evaluation procedures' ability to predict futuredaughter yield.

First-parity milk yield of future Holstein daughters in the Northeast had a higher correlation (0.01 to 0.02) with USDA evaluations than with MT-CASE evaluations during 1994 and 1995 (Table 4), even though the latter used a test-day model. Dairy producers in the Northeast who relied exclusively on regional Holstein evaluations from 1976 through 1987 and during 1994 and 1995 made less genetic progress than did those who used national Holstein evaluations if their extent of AI use and selection practices were similar.

Effectiveness of released USDA evaluations based on all lactations in predicting first-parity milk yield of future Northeast Holstein daughters was compared 
Table 5. Correlations ${ }^{1}$ between regional and national genetic evaluations ${ }^{2}$ for milk yield for Holstein bulls based on first or all daughter parities by region.

\begin{tabular}{|c|c|c|c|c|c|c|c|}
\hline \multirow[b]{3}{*}{ Region } & \multirow[b]{3}{*}{ Bulls $^{3}$} & \multirow[b]{3}{*}{ Parity } & \multirow[b]{3}{*}{ Evaluation } & \multicolumn{4}{|c|}{ Correlations between evaluations } \\
\hline & & & & \multicolumn{2}{|c|}{ All parities } & \multicolumn{2}{|c|}{ Parity 1} \\
\hline & & & & National & Regional & National & Regional \\
\hline \multirow{5}{*}{ California } & (no.) & & & & & & \\
\hline & 4900 & All & National & 1.000 & 0.907 & 0.931 & 0.845 \\
\hline & & & Regional & 0.907 & 1.000 & 0.850 & 0.914 \\
\hline & & 1 & National & 0.931 & 0.850 & 1.000 & 0.911 \\
\hline & & & Regional & 0.845 & 0.914 & 0.911 & 1.000 \\
\hline \multirow[t]{4}{*}{ North Central } & 7159 & All & National & 1.000 & 0.954 & 0.940 & 0.901 \\
\hline & & & Regional & 0.954 & 1.000 & 0.898 & 0.939 \\
\hline & & 1 & National & 0.940 & 0.898 & 1.000 & 0.947 \\
\hline & & & Regional & 0.901 & 0.939 & 0.947 & 1.000 \\
\hline \multirow[t]{4}{*}{ Northeast } & 5390 & All & National & 1.000 & 0.964 & 0.935 & 0.902 \\
\hline & & & Regional & 0.964 & 1.000 & 0.899 & 0.929 \\
\hline & & 1 & National & 0.935 & 0.899 & 1.000 & 0.955 \\
\hline & & & Regional & 0.902 & 0.929 & 0.955 & 1.000 \\
\hline \multirow[t]{4}{*}{ Southeast } & 2335 & All & National & 1.000 & 0.887 & 0.948 & 0.842 \\
\hline & & & Regional & 0.887 & 1.000 & 0.836 & 0.927 \\
\hline & & 1 & National & 0.948 & 0.836 & 1.000 & 0.875 \\
\hline & & & Regional & 0.842 & 0.927 & 0.875 & 1.000 \\
\hline
\end{tabular}

with USDA evaluations based on only first-parity records. First-parity evaluations were calculated by USDA from 1974 through 1989 but were not released to producers (USDA, unpublished data); first-parity evaluations were not calculated after the animal model was implemented (i.e., for 1994 and 1995). The unreleased USDA first-parity evaluations were slightly more effective for predicting first-parity yield than were released USDA evaluations based on all parities; mean correlation of evaluations from 1976 through 1987 with first-parity yield of future Holstein daughters was 0.117 for first-parity evaluations and 0.113 for all-parity evaluations. The inclusion of laterparity records in released USDA evaluations did not increase accuracy of prediction of first-parity yield from Northeast Holsteins, which is reasonable if the genetic correlation between first- and later-parity yield is <1 (Cassell and McDaniel, 1983). The higher correlation with Northeast future-daughter yield for USDA first-parity evaluations (0.117) compared with NEAISC evaluations (0.100) illustrates the benefit of including information from more daughters in the evaluation even though the daughters are located outside the region. Powell et al. (2000) have shown that including additional information from daughters that are located in other countries improves the ability of sire evaluations to predict yield of future daughters; therefore, including additional information from daughters from other regions within a country would be expected to be beneficial as well.

The effectiveness of those same 3 evaluation methods for predicting third-parity standardized milk yield of future Northeast Holstein daughters also was compared (Table 4). All-parity USDA evaluations were a better predictor of third-parity yield than were NEAISC evaluations for 8 of 9 yr. All-parity USDA evaluations from 1976 through 1985 had a higher mean correlation (0.089) with third-parity yield of future Northeast daughters than did first-parity USDA evaluations (0.080). Both first- and all-parity USDA evaluations had higher correlations with third-parity yield of future Northeast daughters than did NEAISC evaluations (mean correlation of 0.061). Those findings suggest that reduced accuracy of NEAISC evaluations in predicting third-parity milk yield of future daughters resulted from a failure to include information both from daughters outside the region and from later-parity records in genetic evaluations.

The NEAISC evaluations included EAIC progenytest bulls as well as widely used bulls that were marketed by most AI organizations. In contrast, most progeny-test bulls from AI organizations other than EAIC were not included in Northeast evaluations because they had too few daughters there. Most of the nonEAIC bulls had Northeast evaluations released only after having some second-crop daughters that were milking. 
Table 6. Numbers of lactation records and herd-year-seasons ${ }^{1}$ for Holstein cows that completed those records after calculation of evaluations for their sires and correlations within herd-year-season of regional and national genetic evaluations ${ }^{2}$ for Holstein bulls based on first or all daughter parities with standardized ${ }^{3}$ milk yield of future daughters in the region by parity and region.

\begin{tabular}{|c|c|c|c|c|c|c|c|}
\hline \multirow{3}{*}{$\begin{array}{l}\text { Future- } \\
\text { daughter } \\
\text { parity }\end{array}$} & \multirow[b]{3}{*}{ Region } & \multirow[b]{3}{*}{ Records } & \multirow{3}{*}{$\begin{array}{l}\text { Herd-year- } \\
\text { seasons }\end{array}$} & \multicolumn{4}{|c|}{ Correlations between evaluations } \\
\hline & & & & \multicolumn{2}{|c|}{ All parities } & \multicolumn{2}{|c|}{ Parity 1} \\
\hline & & & & National & Regional & National & Regional \\
\hline & & $\longrightarrow$ & o.) & & & & \\
\hline \multirow[t]{4}{*}{1} & California & 218,697 & 12,006 & 0.110 & 0.102 & 0.115 & 0.100 \\
\hline & North Central & 766,026 & 157,946 & 0.117 & 0.116 & 0.121 & 0.120 \\
\hline & Northeast & 500,401 & 96,768 & 0.126 & 0.125 & 0.131 & 0.130 \\
\hline & Southeast & 98,306 & 15,910 & 0.118 & 0.107 & 0.117 & 0.104 \\
\hline \multirow[t]{4}{*}{2} & California & 155,558 & 11,489 & 0.128 & 0.119 & 0.097 & 0.078 \\
\hline & North Central & 500,166 & 138,325 & 0.129 & 0.125 & 0.098 & 0.097 \\
\hline & Northeast & 349,094 & 86,261 & 0.137 & 0.135 & 0.103 & 0.102 \\
\hline & Southeast & 62,270 & 13,719 & 0.130 & 0.126 & 0.097 & 0.094 \\
\hline \multirow[t]{4}{*}{3} & California & 103,170 & 10,238 & 0.122 & 0.114 & 0.089 & 0.069 \\
\hline & North Central & 310,757 & 111,945 & 0.122 & 0.118 & 0.089 & 0.089 \\
\hline & Northeast & 227,454 & 71,431 & 0.129 & 0.128 & 0.089 & 0.091 \\
\hline & Southeast & 37,545 & 10,734 & 0.129 & 0.114 & 0.097 & 0.087 \\
\hline
\end{tabular}

\footnotetext{
${ }^{1}$ Seasons defined as January to June and July to December.

${ }^{2}$ Calculated with current USDA-DHIA animal model and lactation records of bull daughters with a first calving date before January 1, 1992.

${ }^{3}$ Mature-equivalent basis for age, calving month, milking frequency, and lactation length.
}

Because nonEAIC bulls had only a portion of their daughter information included in NEAISC evaluations, their evaluations were regressed more than in USDA evaluations. The smaller range of their evaluations restricted their opportunity to rank among the highest NEAISC bulls. For both EAIC and nonEAIC bulls, USDA evaluations predicted first-parity milk yield of future daughters with greater or the same accuracy as NEAISC evaluations for 11 of $12 \mathrm{yr}$ (not shown in tables). Mean correlation of evaluations from 1976 through 1987 with first-parity yield was 0.109 for USDA evaluations and 0.094 for NEAISC evaluations for EAIC bulls and 0.097 and 0.090 , respectively, for nonEAIC bulls. Differences between mean correlations of NEAISC and USDA evaluations with milk yield of future daughters were less for nonEAIC bulls than for EAIC bulls. Correlations between evaluations and future-daughter yield were lower for nonEAIC bulls than for EAIC bulls for both evaluation methods, which was expected because most nonEAIC bulls had been returned to AI service after the progeny test and, therefore, had higher reliability and less variation in genetic merit among bulls than did EAIC bulls. Mean USDA reliability for nonEAIC bulls was 90 to $99 \%$ each year, whereas mean reliability for EAIC bulls was 79 to $87 \%$.

\section{Determination of Potential Benefit from Regional Sire Evaluation}

The same data edits and statistical model were used in this analysis to compute regional and national Hol- stein evaluations; therefore, the interpretation of differences among evaluations should not be confounded by differences in regional data and methodology even though more current milk records from more regions were examined than in the historical comparison between Northeast and national evaluations. This approach also increased the number of bulls with regional evaluations available for analysis (2335 for Southeast to 7159 for North Central, Table 5) compared with analysis of only bulls with both released USDA and Northeast evaluations. Correlations between national and regional evaluations for milk yield calculated within birth year of bull (Table 5) ranged from 0.88 to 0.96 when information from the same parities was included in the evaluation and were greater in North Central (0.95) and Northeast (0.96) regions than in California (0.91) and the Southeast ( 0.88 for first-parity evaluations and 0.89 for all-parity evaluations). Although the 2 regions with the highest correlations also had the most data, whether the additional data were the primary contributing factor is not known.

Correlations of national and regional genetic evaluations with standardized milk yield of future daughters within the same region (Table 6) were similar in range and relative differences to correlations of USDA and NEAISC evaluations with standardized milk yield of future Northeast daughters (Table 4). Correlations for national evaluations based on all parities were slightly higher $(0.001$ to 0.011$)$ than for regional allparity evaluations (Table 6). National and regional all- 
Table 7. Numbers of lactation records and herd-year-seasons ${ }^{1}$ for Holstein cows that completed those records after calculation of evaluations for their sires and correlations within herd-year-season of regional and national genetic evaluations ${ }^{2}$ for Holstein bulls based on first or all daughter parities with standardized ${ }^{3}$ milk yield of all future US daughters by parity and region.

\begin{tabular}{|c|c|c|c|c|c|c|c|}
\hline \multirow{3}{*}{$\begin{array}{l}\text { Future- } \\
\text { daughter } \\
\text { parity }\end{array}$} & \multirow[b]{3}{*}{ Region } & \multirow[b]{3}{*}{ Records } & \multirow{3}{*}{$\begin{array}{l}\text { Herd-year- } \\
\text { seasons }\end{array}$} & \multicolumn{4}{|c|}{ Correlations between evaluations } \\
\hline & & & & \multicolumn{2}{|c|}{ All parities } & \multicolumn{2}{|c|}{ Parity 1} \\
\hline & & & & National & Regional & National & Regional \\
\hline & & - & .) & & & & \\
\hline \multirow[t]{4}{*}{1} & California & $1,549,477$ & 265,238 & 0.124 & 0.110 & 0.127 & 0.106 \\
\hline & North Central & $2,208,928$ & 319,689 & 0.113 & 0.106 & 0.118 & 0.110 \\
\hline & Northeast & $1,798,745$ & 292,353 & 0.121 & 0.115 & 0.123 & 0.117 \\
\hline & Southeast & $1,347,161$ & 251,640 & 0.123 & 0.100 & 0.128 & 0.101 \\
\hline \multirow[t]{4}{*}{2} & California & $1,045,083$ & 229,907 & 0.133 & 0.122 & 0.102 & 0.080 \\
\hline & North Central & $1,484,379$ & 281,483 & 0.126 & 0.117 & 0.096 & 0.090 \\
\hline & Northeast & $1,217,369$ & 255,170 & 0.131 & 0.125 & 0.096 & 0.092 \\
\hline & Southeast & 910,282 & 217,775 & 0.135 & 0.119 & 0.105 & 0.091 \\
\hline \multirow[t]{4}{*}{3} & California & 663,144 & 183,242 & 0.125 & 0.114 & 0.091 & 0.072 \\
\hline & North Central & 939,375 & 228,982 & 0.119 & 0.112 & 0.087 & 0.086 \\
\hline & Northeast & 773,506 & 205,064 & 0.121 & 0.116 & 0.086 & 0.083 \\
\hline & Southeast & 577,529 & 172,527 & 0.123 & 0.108 & 0.093 & 0.078 \\
\hline
\end{tabular}

${ }^{1}$ Seasons defined as January to June and July to December.

${ }^{2}$ Calculated with current USDA-DHIA animal model and lactation records of bull daughters with a first calving date before January 1, 1992.

${ }^{3}$ Mature-equivalent basis for age, calving month, milking frequency, and lactation length.

parity evaluations predicted first-parity standardized milk yield of future daughters within the region more effectively than first-parity evaluations predicted later-parity yield; first-parity evaluations predicted first-parity yield better by 0.010 to 0.042 than they predicted later-parity yield, and all-parity evaluations predicted second- and third-parity yields better by 0.002 to 0.019 than they predicted first-parity yield. Overall, national all-parity evaluations predicted combined yield from the first 3 parities of future daughters within the region best followed by regional all-parity evaluations. First-parity evaluations were substantially poorer predictors of future-daughter yield within region than were all-parity evaluations, but national first-parity evaluations were considerably better predictors than were regional first-parity evaluations. National evaluations always predicted first- and second-parity yields within region at least slightly better (0.001 to 0.019$)$ than did regional evaluations. National first-parity evaluations predicted third-parity yield within region better than regional first-parity evaluations in California (0.020) and the Southeast (0.010) but did not in the North Central $(0.000)$ or Northeast $(-0.002)$ regions.

National evaluations predicted yields of all future US daughters (Table 7) better than did regional evaluations based on the same parity grouping regardless of region or parity of future daughters. Effectiveness of regional and national bull evaluations in predicting lactation yields of future daughters nationally (Table
7) vs. within region (Table 6) can indicate relative size of genotype-environment interaction between each region and the entire United States. The accuracy of North Central and Northeast evaluations was closer to national evaluation accuracy in predicting futuredaughter yield both nationally and within region than was California and Southeast evaluation accuracy. Regional evaluations generally predicted future-daughter yield more accurately within region than nationally; however, California evaluations were better predictors of yields for all future US daughters than for future California daughters. Although an obvious reason for those findings is not known, the percentage of misidentified sires may have been an influence. To predict combined yield from the first 3 parities (not shown), national evaluations based on all parities through fifth again were the most effective, whereas regional evaluations based only on first parities were the least effective.

The comparisons of USDA and NEAISC evaluations and of national and regional evaluations add evidence to the hypothesis that genetic correlations among parities are $<1.0$, which has been consistently reported in other studies (Powell et al., 1981; Cassell and McDaniel, 1983; Cassell et al., 1985; Jamrozik et al., 1998). One purpose of regional genetic evaluations is to avoid bias from production environments that vary throughout the country. However, any gain from considering the effect of genotype-environment interaction in regional evaluations appears to have been offset by the 
Table 8. Additional standardized ${ }^{1}$ daughter milk yield ${ }^{2}$ from selecting as sires the top 25,50 , or 100 Holstein bulls for mean PTA milk based on USDA genetic evaluations instead of the top 25, 50, or 100 bulls based on regional evaluations by parities included in the regional evaluation, region, and evaluation year.

\begin{tabular}{|c|c|c|c|c|c|}
\hline \multirow{2}{*}{$\begin{array}{l}\text { Parities } \\
\text { included } \\
\text { in evaluation }\end{array}$} & \multirow[b]{2}{*}{ Region } & \multirow[b]{2}{*}{$\begin{array}{l}\text { Evaluation } \\
\text { year }\end{array}$} & \multicolumn{3}{|c|}{$\begin{array}{l}\text { Yield increase from selecting sires based on } \\
\text { national rather than regional evaluation }\end{array}$} \\
\hline & & & $\begin{array}{l}\text { Top } 25 \\
\text { bulls }\end{array}$ & $\begin{array}{l}\text { Top } 50 \\
\text { bulls }\end{array}$ & $\begin{array}{l}\text { Top } 100 \\
\text { bulls }\end{array}$ \\
\hline & & & & - $(\mathrm{k}$ & \\
\hline \multirow{4}{*}{ All } & California & 1992 & 71 & 68 & 71 \\
\hline & North Central & 1992 & 28 & 49 & 52 \\
\hline & Northeast & 1992 & 85 & 97 & 101 \\
\hline & Southeast & 1992 & 68 & 88 & 114 \\
\hline \multirow[t]{6}{*}{ First } & California & 1992 & 28 & 35 & 42 \\
\hline & North Central & 1992 & 30 & 23 & 25 \\
\hline & Northeast & 1992 & 75 & 83 & 85 \\
\hline & & 1994 & 84 & 116 & 173 \\
\hline & & 1995 & 87 & 123 & 172 \\
\hline & Southeast & 1992 & 86 & 111 & 121 \\
\hline
\end{tabular}

${ }^{1}$ Mature-equivalent basis for age, calving month, milking frequency, and lactation length.

${ }^{2}$ Expected increase for 1992 regional evaluations, which were calculated with current USDA-DHIA animal model and lactation records of bull daughters with a first calving date before January 1, 1992; realized increase for 1994 and 1995 Northeast evaluations (July release of Northeast Multiple-Trait Cow and Sire Evaluation), which were calculated with a multiple-trait test-day model.

gain in accuracy from the greater number of records used to calculate national evaluations. Observed differences in effectiveness of predicting yield from different parities indicates that a multitrait model that included genetic correlations of $<1.0$ between parities might improve genetic estimates. However, such a model would be computationally more demanding, especially for large populations. As computer speed increases, the feasibility of using such a model should be examined periodically.

Producers should expect additional daughter milk yield by using the top bulls based on national rather than regional evaluations (Table 8). Fewer bulls had regional evaluations because of fewer daughters in each geographical area; therefore, the bulls with the highest regional evaluations for milk yield were inferior to the bulls with the highest national evaluations. Based on differences in means between groups of bulls with the highest genetic merit regionally or nationally, the expected additional standardized daughter milk yield if selection was on all-parity national evaluations ranged from 28 to $85 \mathrm{~kg}$ for the top 25,49 to $97 \mathrm{~kg}$ for the top 50, and 52 to $114 \mathrm{~kg}$ for the top 100 bulls if regional evaluations also were based on all parities. For evaluations based on first-parity records, the advantage was similar if selection decisions were based on national rather than regional evaluations. The greatest differences were found between released USDA and Northeast MT-CASE evaluations. Mean milk yield of daughters was higher for the top 25 bulls nationally in 1994 and 1995 by 84 and $87 \mathrm{~kg}$, respec- tively, than for the top 25 bulls based on Northeast MT-CASE evaluations; corresponding differences were 116 and $123 \mathrm{~kg}$ for the top 50 bulls and 173 and $172 \mathrm{~kg}$ for the top 100 bulls. Increased reliance on regional evaluations would reduce current rates of US genetic improvement for dairy cattle.

\section{CONCLUSIONS}

The historic examination of the ability of released NEAISC and USDA evaluations to predict standardized milk yield of future daughters showed that USDA evaluations from 1976 to 1987 were better predictors of lactation milk yield of future daughters than were NEAISC evaluations both nationally and in the Northeast. Mean correlations of USDA evaluations with first-, second-, and third-parity yields of future daughters were higher than for NEAISC evaluations. No interaction between genotype and environment was found between the Northeast and the entire United States.

When national and regional evaluations were computed with identical data edits and evaluation procedures, national evaluations based on all parities were the best predictors of future-daughter yield; regional evaluations based on first-parity records were the least accurate predictors. Many of the best bulls genetically do not have enough daughters within a region to meet requirements to be included in the released regional evaluation; therefore, national evaluations can include many more bulls than do regional evaluations. 
Exclusive use of regional evaluations without consideration of national ranking could be extremely misleading if breeders are not aware of evaluation limitations.

Genetic evaluations currently based on 5 parities are more predictive of future-daughter yield than are those based on a single parity. Inclusion of more data on an animal and its relatives increases evaluation accuracy, which can lead to greater genetic gain. Improvement in evaluation accuracy from accounting for effect of genotype-environment interaction often is not sufficient to overcome accuracy loss from having information from fewer daughters and records. Models with multiple regions, parities, and traits would be needed to offset the shortfalls from limiting the number of parities included and ignoring daughters in other regions.

\section{ACKNOWLEDGMENTS}

The cooperation of the US dairy industry in supplying yield and pedigree data through the National Genetic Improvement Program for use in calculation of genetic evaluations is acknowledged. Questions and suggestions by California DHIA (Clovis, CA) directors P. Maddox and M. Mulas led to the examination of the potential benefit of calculating regional sire evaluations. The assistance of the staff at the Animal Improvement Programs Laboratory, ARS, USDA (Beltsville, MD) is appreciated for data entry of NEAISC reports (J. H. Megonigal, Jr., F. A. Ross, Jr., and W. E. Shainline, Jr.); calculation of regional evaluations (J. H. Megonigal, Jr., and L. M. Walton); and manuscript review (S. M. Hubbard). Comments and suggestions by the anonymous Journal of Dairy Science reviewers were greatly appreciated.

\section{REFERENCES}

Arnold, F. J. 1956. Fifty years of D.H.I.A. work. J. Dairy Sci. 39:792-794.

Benson, R. H. 1985. The NCDHIP record plans. Natl. Coop. DHI Progr. Handbook, Fact Sheet A-4. Ext. Serv., USDA, Washington, DC.

California DHIA. 2003. AI bulls of the California DHIA. Calif. Dairy. 12(1):8-11.

Carabaño, M. J., K. M. Wade, and L. D. Van Vleck. 1990. Genotype by environment interactions for milk and fat production across regions of the United States. J. Dairy Sci. 73:173-180.

Cassell, B. G., J. S. Clay, and H. D. Norman. 1985. Differences in Modified Contemporary Comparison sire evaluations from first and later lactations by breed. J. Dairy Sci. 68:1778-1784.

Cassell, B. G., and B. T. McDaniel. 1983. Use of later records in dairy sire evaluation: A review. J. Dairy Sci. 66:1-10.

Dickinson, F. N., H. D. Norman, R. L. Powell, L. G. Waite, and B. T. McDaniel. 1976. Procedures used to calculate the USDADHIA Modified Contemporary Comparison. Prod. Res. Rep. 165:18-34. ARS, USDA, Washington, DC.
Everett, R. W., and C. R. Henderson. 1972. The Northeast AI Sire Comparison. Why? Anim. Sci. Mimeo. Ser. No. 19. Dept. Anim. Sci., Cornell Univ., Ithaca, NY.

Everett, R. W., and R. L. Quaas. 1979. Sire Evaluation in the Northeast. Anim. Sci. Mimeo. Ser. No. 44. Dept. Anim. Sci., Cornell Univ., Ithaca, NY.

Everett, R. W., R. L. Quaas, and A. E. McClintock. 1979. Daughters' maternal grandsires in sire evaluation. J. Dairy Sci. 62:13041313.

Everett, R. W., R. L. Quaas, and E. J. Pollak. 1983. Multiple Trait Northeast Artificial Insemination Sire Comparison. Anim. Sci. Mimeo. Ser. No. 74. Coop. Ext., Dept. Anim. Sci., Cornell Univ., Ithaca, NY.

Everett, R. W., and F. Schmitz. 1994. Dairy Genetics in 1994 and Beyond. Anim. Sci. Mimeo Ser. No. 170. Cornell Univ., Ithaca, NY. Online. Available: http://www.ansci.cornell.edu/tmplobs/ doc2.pdf. Accessed Apr. 9, 2004

Henderson, C. R. 1966. Sire evaluation method which accounts for unknown genetic and environmental trends, herd differences, season, age effects, and differential culling. Pages 172-204 in Symp. on Estimating Breeding Values of Dairy Sires and Cows. Dairy Cattle Res. Branch, Anim. Husbandry Res. Div., ARS, USDA, Washington, DC

Henderson, C. R. 1975. Inverse of a matrix of relationships due to sires and maternal grandsires. J. Dairy Sci. 58:1917-1921.

Henderson, C. R., H. W. Carter, and J. T. Godfrey. 1954. Use of the contemporary herd average in appraising progeny tests of dairy bulls. J. Anim. Sci. 13:949. (Abstr.)

Hodgson, R. E. 1986. Dairy production research by the United States Department of Agriculture, 1895 to 1980: A historical review. USDA Misc. Publ. 1447:1-57. ARS, USDA, Washington, DC.

Interbull. 2004a. Description of National Genetic Evaluation Systems for dairy cattle traits as applied in different Interbull member countries. Online. Available: http://www-interbull.slu.se/ national_ges_info2/begin-ges.html. Accessed June 25, 2004

Interbull. 2004b. Interbull routine genetic evaluation for dairy production traits, May 2004. Online. Available: http://www-interbull.slu.se/eval/may04.html. Accessed June 23, 2004.

Jamrozik, J., L. R. Schaeffer, and F. Grignola. 1998. Genetic parameters for production traits and somatic cell score of Canadian Holsteins with multiple trait random regression model. Proc. 6th World Congr. Genet. Appl. Livest. Prod. 23:303-306.

King, G. J. 1973. The National Cooperative Dairy Herd Improvement Program: History, purpose, and organization. ARS-NE29. DHI Lett. 49:1-57. Anim. Phys. Genet. Inst., ARS, USDA, Beltsville, MD.

Miller, P. D. 1973. A recent study of age adjustment. J. Dairy Sci. 56:952-958.

National Association of Animal Breeders. 2003. Stud code numbers assigned. NAAB Electronic Resource Guide. Online. Available: http://www.naab-css.org/db/studcode.html. Accessed Feb. 4, 2004.

Norman, H. D. 1976. Theoretical background for the USDA-DHIA Modified Contemporary Comparison Sire Summary procedure. USDA Prod. Res. Rep. 165:8-17. ARS, USDA, Washington, DC.

Norman, H. D., B. T. McDaniel, and F. N. Dickinson. 1972. Modified herdmate comparison procedure that weights deviation yields considering daughters' distribution across herds. J. Dairy Sci. 55:691-692. (Abstr.)

Norman, H. D., P. D. Miller, B. T. McDaniel, F. N. Dickinson, and C. R. Henderson. 1974. USDA-DHIA factors for standardizing 305-day lactation records for age and month of calving. ARSNE-40. ARS, USDA, Beltsville, MD.

Norman, H. D., R. L. Powell, and J. R. Wright. 1987. Influence of genetic differences in merit of mates on sire evaluation. J. Dairy Sci. 70:141-157.

Norman, H. D., R. L. Powell, J. R. Wright, and C. G. Sattler. 2001. Overview of progeny-test programs of artificial insemination organizations in the United States. J. Dairy Sci. 84:1899-1912.

Norman, H. D., R. L. Powell, J. R. Wright, and C. G. Sattler. 2003. Timeliness and effectiveness of progeny testing through artificial insemination. J. Dairy Sci. 86:1512-1525. 
Plowman, R. D., and B. T. McDaniel. 1968. Changes in USDA Sire Summary procedures. J. Dairy Sci. 51:306-311.

Powell, R. L., and H. D. Norman. 1986. Genetic and environmental differences between registered and grade Holstein cows. J. Dairy Sci. 69:2897-2907.

Powell, R. L., and H. D. Norman. 1988. Accuracy of cow indexes according to repeatability, evaluation, herd yield, and registry status. J. Dairy Sci. 71:2232-2240.

Powell, R. L., H. D. Norman, and G. Banos. 2000. Improving prediction of national evaluations by use of data from other countries. J. Dairy Sci. 83:368. Online. Available: http://www.adsa.org/jds/ papers/2000/online/jds9123.htm.

Powell, R. L., H. D. Norman, and R. M. Elliott. 1981. Different lactations for estimating genetic merit of dairy cows. J. Dairy Sci. 64:321-330.

Rekaya, R., K. A. Weigel, and D. Gianola. 2003. Bayesian estimation of parameters of a structural model for genetic covariances between milk yield in five regions of the United States. J. Dairy Sci. 86:1837-1844.

VanRaden, P. M., G. R. Wiggans, R. L. Powell, and H. D. Norman. 1995. Changes in USDA-DHIA genetic evaluations (January 1995). AIPL Res. Rep. CH3(1-95). Online. Available: http:// aipl.arsusda.gov/reference/changes/chng951.pdf. Accessed May 27, 2004.
VanRaden, P. M., G. R. Wiggans, and C. P. Van Tassell. 1999. Changes in USDA-DHIA genetic evaluations (February 1999). AIPL Res. Rep. CH13(2-99). Online. Available: http://aipl.arsusda.gov/reference/changes/chng9902.html. Accessed May 27, 2004.

VerBoort, B. 2003. Thinking outside the box. Calif. Dairy. 12(1): 3,14 .

Weigel, K. A., and R. L. Powell. 2000. Retrospective analysis of the accuracy of conversion equations and multiple-trait, acrosscountry evaluations of Holstein bulls used internationally. J. Dairy Sci. 83:1081-1088.

Wiggans, G. R., and F. N. Dickinson. 1985. Standardization of NCDHIP dairy cattle lactation records. Natl. Coop. DHI Progr. Handbook, Fact Sheet G-2. Ext. Serv., USDA, Washington, DC.

Wiggans, G. R., and R. L. Powell. 1980. Projection factors for milk and fat lactation records. DHI Lett. 56:1-15. USDA, Beltsville, MD.

Wiggans, G. R., and P. M. VanRaden. 1989. USDA-DHIA animal model genetic evaluations. Natl. Coop. DHI Progr. Handbook, Fact Sheet H-2. Ext. Serv., USDA, Washington, DC.

Wiggans, G. R., and L. D. Van Vleck. 1979. Extending partial lactation milk and fat records with a function of last-sample production. J. Dairy Sci. 62:316-325.

Wilmink, J. B. M., A. Meijering, and B. Engel. 1986. Conversions of breeding values for milk from foreign populations. Livest. Prod. Sci. 14:223-229. 